\title{
Stability-indicating LC method for the quantification of Midazolam active pharmaceutical ingredient and in pharmaceutical formulations
}

\author{
Daiane Anzilaggo ${ }^{a}$, Bádila Regina Dalla Costa ${ }^{a}$, Luciana \\ Grazziotin Rossato-Grando ${ }^{a}$, Hellen Karine Stulzer ${ }^{b}$ and Charise Dallazem Bertol ${ }^{a *}$
}

\begin{abstract}
${ }^{a}$ Laboratório de Controle de Qualidade, Curso de Farmácia, Programa de Pós-Graduação em Envelhecimento Humano, Universidade de Passo, Av Brasil Leste, 285, São José, 99052-900, Passo Fundo-RS, Brazil

${ }^{\mathrm{b}}$ Universidade Federal de Santa Catarina, R. Eng. Agronômico Andrei Cristian Ferreira, s/n, Trindade,88040-900, Florianópolis
\end{abstract} $-S C$, Brazil

*Corresponding author: charise@upf.br

A stability-indicating LC method was validated for the quantification of midazolam (MDZ) active pharmaceutical ingredient (API) and in pharmaceutical formulations. Isocratic chromatography was performed on $\mathrm{C}_{18}$ column with mobile phase containing methanol/acetonitrile/water $(45: 35: 20 \mathrm{v} / \mathrm{v} / \mathrm{v})$ with $0.4 \%$ of triethylamine $\mathrm{pH} 6.5$. The validation included specificity, linearity, accuracy, precision and robustness. In specificity, after hydrolytic (acid, basic, water), oxidant and thermal degradation, it was found that the concentration of MDZ decreased substantially, with the appearance of peaks representatives of the degradation products, proving the stability-indicating potential of the method. The response was linear in the range $50.0-250.0 \mu \mathrm{g} . \mathrm{mL}^{-1}$, with $11.73 \mu \mathrm{g} . \mathrm{mL}^{-1}$ and $3.87 \mu \mathrm{g} . \mathrm{mL}^{-1}$ as LOQ and LOD, respectively. Recoveries ranged between 98.68 and $100.41 \%$. The relative standard deviation values for intra and interday precision were $1.11 \%$ (day 1), $0.82 \%$ (day 2) and $1.47 \%$ (day 3 ), respectively. The tablets and injections containing MDZ were approved in the assay and content uniformity. The method can be adopted by pharmacopeias and for routine quality control for analysis of MDZ API, tablets and injection.

Keywords: Forced degradation. HPLC. Injections. Quality control. Stress test. Tablets.

\section{Introduction}

Pharmacological sedation and anxiolysis is a common practice in anesthesia and the anesthetics used should be easy of application, rapid action, short duration action (short half-life), and few adverse events. Benzodiazepines are the safest class of drugs for this purpose. In this context, MDZ has all these characteristics, hence is the most commonly used in anesthetic procedures of hospitals $(1,2,3)$. MDZ exhibits anticonvulsant, anxiolytic, muscle relaxant and sedative properties, used in sleep disorder or induction of anesthesia, orally, intravenously or intramuscularly routes. It reduces behavioral problems in postoperative with presence of anterograde amnesia induced (4). MDZ acts on the central nervous system (CNS) potentiating the effects of Gammaaminobutyric acid (GABA agonist) which is the main inhibitor of the CNS $(5,6)$. This compound is a weak acid with a pKa of 6.2 in water (4). The solubility in water is approximately $10.3 \mathrm{mg} \cdot \mathrm{mL}^{-1}$ $\left(\mathrm{pH} 3.4,25^{\circ} \mathrm{C}\right)(7) . \mathrm{MDZ}$ is available commercially in tablet and injection forms (8). Several methods by LC are described for MDZ quantification and its metabolites in biological matrices of humans, rats and rabbits plasma $(9,10)$, as well methods to evaluate the quality of pharmaceutical formulations, compiled in the review (11). The British Pharmacopoeia describes the monograph for MDZ active pharmaceutical ingredient (API) and for injections. API assays have been performed by titration, being unable to detect degradation products (12). The pharmacopeias do not describe the monograph to evaluate tablets. Furthermore, to detect degradation products it is require more sensitive techniques.
The Brazilian Pharmacopeia does not present monographs for MDZ for any of that forms, included the API. ICH (13) recommends that a method should be able to detect degradation products from stress test or impurities, but these degradations products should not interfere in the quantification of the drug.

In this way, the aim of the work was to develop and validate a stability-indicating method by LC for the quantification of MDZ and its application in tablets and injections. The quality of tablets and injections were evaluated by assay and uniformity content.

\section{Experimental}

\section{Chemicals and materials}

MDZ API was purchased from Fagron, São Paulo/SP/Brazil, and the purity was determined by titration (12) (Titrino 702 SM, Methrom Pensalab, São Paulo/SP/Brazil) being $99.5 \%$ $\pm 0.83 \%$. The tablets (15 mg MDZ, Roche, Jaguaré/SP/Brazil) and injections (50 mg. $\mathrm{mL}^{-1} \mathrm{MDZ}$, União Química, São Paulo/SP/Brazil) were kindly donated by Hospital São Vicente de Paulo, Passo Fundo, Rio Grande do Sul, Brazil. The reagents used were HPLC grade. The water type 1 was obtained in Direct-Q system from Millipore ${ }^{\circledR}$.

\section{Instruments and analytical conditions}

LC system consisted of a Flexar Perkin Elmer (Shelton/CT/ USA) liquid chromatography, equipped with binary pump, PDA detector in $235 \mathrm{~nm}$, and autosampler with injection 
volume of $20 \mu \mathrm{L}$. The chromatograph separation was carried out using a reversed phase column Brownlee $\mathrm{C}_{18}(250 \mathrm{~mm} \mathrm{x}$ $4.6 \mathrm{~mm}$, $5 \quad \mu \mathrm{m})$. The mobile phase consisted of methanol:acetonitrile:water $(45: 35: 20 \mathrm{v} / \mathrm{v} / \mathrm{v})$ with $0.4 \%$ triethylamine and $\mathrm{pH}$ adjusted to 6.5 with phosphoric acid. The elution was isocratic with a flow rate of $1.0 \mathrm{~mL} . \mathrm{min}^{-1}$. The peak areas were integrated automatically by software Chromera Flexar.

\section{Preparation of MDZ Solution}

A stock standard solution of $500.0 \mu \mathrm{g} \cdot \mathrm{mL}^{-1}$ was prepared by dissolving MDZ API in methanol in a volumetric flask.

\section{Method Validation}

For the validation of the method the following parameters were studied: specificity, linearity, limit of quantitation and detection, accuracy, precision and robustness (13) using the MDZ API.

\section{Specificity}

In order to determine the specificity, MDZ solutions (500.0 $\left.\mu \mathrm{g} \cdot \mathrm{mL}^{-1}\right)$ were submitted to forced degradation. The acid, alkaline and neutral degradation were performed by diluting the sample in $0.1 \mathrm{~mol} . \mathrm{L}^{-1} \mathrm{HCl}, 0.1 \mathrm{~mol} . \mathrm{L}^{-1} \mathrm{NaOH}$, and purified water, respectively at room temperature for 6 days. Oxidative degradation was induced by storing the sample diluted with $30 \%$ hydrogen peroxide at room temperature for 6 days, protected from light. To investigate drug stability under thermal stress, the solution was kept in an oven at $80^{\circ} \mathrm{C}$ for 3 days. The photolysis studies were conducted through the exposure of solutions under $254 \mathrm{~nm}$ UV light for 7, 12 and 25 days. After the procedures, the samples were neutralized and diluted with methanol to a final concentration of $150.0 \mu \mathrm{g} \cdot \mathrm{mL}^{-1}$ and analyzed. Photolysis degradation kinetic was performed. To determine the order reaction three graphs were constructed: Percentage degradation versus time (days) (order zero), log of the percentage of degradation versus time (days) (first order); $1 /$ concentration (\%) versus time (days) (second order). The best correlation coefficient of the straight line (r) defines the order of the reaction (14). After the definition of the order reaction, it was possible to calculate the $\mathrm{K}$ (degradation rate constant, days ${ }^{-1}$ ) (equation 1), and $\mathrm{t}_{50 \%}$ (half-life in this condition, namely the time required for degrading $50 \%$ drug) (equation 2).

$$
\begin{aligned}
& \mathbf{K}=\mathbf{C}_{0}-\mathbf{C} / \mathbf{T}(\mathbf{1}) \\
& \mathbf{t}_{50 \%}=\mathbf{C}_{0} / 2 \mathrm{~K}(\mathbf{2})
\end{aligned}
$$

Where " $\mathrm{C}_{0}$ " is the initial concentration and " $\mathrm{C}$ " is the last measured concentration at time " $t$ ".

\section{Linearity, Limits of detection (LOD) and quantitation (LOQ)}

Linearity was determined by preparing of three calibration curves containing five concentration of $\operatorname{MDZ}$ (50.0, 100.0,
150.0, 200.0 e $250.0 \mu \mathrm{g} . \mathrm{mL}^{-1}$ ) in methanol. The injections were made in triplicate to verify the repeatability of the detector response. The peak areas of the chromatograms were plotted versus the concentration to obtain the calibration curve. The curves were subjected to ANOVA ( $\mathrm{P}$ $<0.05)$ observing the sources of variations linear regression and linearity deviation. The LOD and LOQ were calculated from the slope and standard deviation of the intercept of the mean of three calibration curves.

\section{Accuracy and Precision}

The accuracy of the developed method was evaluated by a recovering test, by analysis of three MDZ concentrations of $60.0 \mu \mathrm{g} . \mathrm{mL}^{-1}, 140.0 \mu \mathrm{g} . \mathrm{mL}^{-1}$ and $240.0 \mu \mathrm{g} . \mathrm{mL}^{-1}$ within the range of the curve, performed in triplicate. The $\%$ recovery was calculated by equation 3 :

\section{$\%$ Recovery $=($ found concentration $) /($ theoretical concentration) $\times 100(3)$}

The intraday precision was evaluated analyzing six MDZ solutions of $140.0 \mu \mathrm{g} . \mathrm{mL}^{-1}$ during the same day, under the same experimental conditions. Interday precision was evaluated analyzing the solutions on three different days. Peak areas were determined and compared. Precision was expressed as percentage relative standard deviation (RSD).

\section{Robustness}

The robustness was established by introducing small changes in the chromatographic system, like flow rate $(0.9$ $\mathrm{mL} \cdot \mathrm{min}^{-1}$ and $\left.1.1 \mathrm{~mL} \cdot \mathrm{min}^{-1}\right)$ and the $\mathrm{pH}$ of the mobile phase (6.3 and 6.7).

\section{Method Application}

\section{Assay of the MDZ tablets and injections}

For quantification of the MDZ in tablets (containing $15 \mathrm{mg}$ MDZ), 20 tablets were weighted and mashed obtaining a pool. A content equivalent to $15 \mathrm{mg}$ of MDZ was added to a $100 \mathrm{~mL}$ volumetric flask and diluted with methanol, in triplicate. Before of injection to the LC system, the solutions were filtered. The concentration of the final solutions was $150.0 \mu \mathrm{g} . \mathrm{mL}^{-1}$.

For quantification of the MDZ injections, 20 ampoules (containing $50.0 \mu \mathrm{g} . \mathrm{mL}^{-1} \mathrm{MDZ}$ ) were mixed. An aliquot of $200 \mu \mathrm{L}$ of the mixture was added to a $10 \mathrm{~mL}$ volumetric flask diluted with methanol or saline solution, in triplicate. Aliquots $(1.5 \mathrm{~mL})$ were removed and added to a $10 \mathrm{~mL}$ volumetric flask obtaining a final concentration of $150.0 \mu \mathrm{g}$. $\mathrm{mL}^{-1}$. The saline solution was used to investigate the stability of the drug in this diluent commonly used in hospitals. The results were analyzed statistically using Student t test $(\mathrm{P}<0.05)$. 
Uniformity of Content

To perform the uniformity of content 10 tablets and 10 injections of the same batch were analyzed separately. Each tablet (containing $15 \mathrm{mg}$ of MDZ) was added individually to $100 \mathrm{~mL}$ volumetric flasks diluted with methanol, obtaining the final concentration of $150.0 \mu \mathrm{g} . \mathrm{mL}^{-1}$. For the injections (50 mg. $\left.\mathrm{mL}^{-1}\right) 200 \mu \mathrm{L}$ were pipetted individually of each injection, added to volumetric flask and completed to $10 \mathrm{~mL}$ with methanol. An aliquot of $1.5 \mathrm{~mL}$ was replaced to $10 \mathrm{~mL}$ volumetric flask, to obtain a final concentration of 150.0

$\mu \mathrm{g} \cdot \mathrm{mL}^{-1}$. The solutions were injected into the LC and the amount of drug was calculated by comparing with a calibration curve prepared on the same day. The acceptance value (AV) was calculated according to British Pharmacopoeia (12).

\section{Results and discussion}

\section{Development and Validation of Method}

The composition of mobile phase was optimized to obtain a better chromatographic condition in a short time of separation. The best peak asymmetry was achieved with a flow rate of $1.0 \mathrm{~mL} \cdot \mathrm{min}^{-1}$ with methanol:acetonitrile:water $(45: 35: 20 \mathrm{v} / \mathrm{v} / \mathrm{v})$ with $0.4 \%$ trielthylamine $\mathrm{pH} 6.5$ as mobile phase. The retention time was about 4 minutes, and a typical chromatogram obtained is shown in fig 1 .

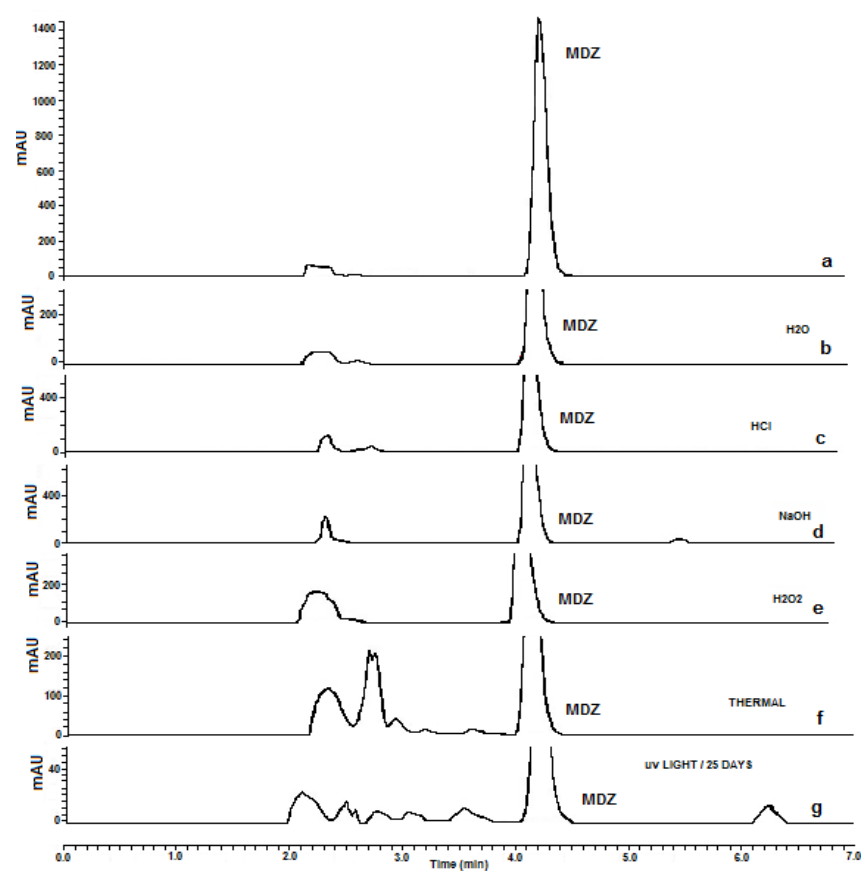

Figure 1. Chromatograms obtained under stress studies. a) MDZ IPA solution $\left(150 \mu \mathrm{g} . \mathrm{mL}^{-1}\right)$; b) After neutral hydrolysis; c) After acid hydrolysis; d) After alkaline hydrolysis; e) After oxidative degradation; f) After thermal degradation; g) After 25 days of exposure in UV light. Chromatographic conditions: $\mathrm{C}_{18}$ column, mobile phase consisting of methanol: acetonitrile: water (45:35:20 $\mathrm{v} / \mathrm{v} / \mathrm{v})$ with $0.4 \%$ triethylamine $\mathrm{pH} 6.5$ under flow rate of 1.0 $\mathrm{mL} \cdot \mathrm{min}^{-1}$ and $\mathrm{UV}$ detection at $235 \mathrm{~nm}$.
The system suitability results showed that the parameters are appropriate and able to produce reliable data. The asymmetry, number of theoretical plates and peak area \pm RSD (\%) were $1.412 \pm 0.075,4,912 \pm 1.65$ and $27,998,796.05 \pm 0.43$, respectively.

\section{Specificity}

The specificity of the method was confirmed by forced degradation (fig 1). From the results of acid, basic, neutral hydrolysis and oxidation during 6 days, the concentration of MDZ decreased $15.36 \%, 9.55 \%, 49.84 \%, 31.95 \%$,

respectively, with the appearance of discrete additional peaks. The thermal stress reduced in $50.38 \%$ the MDZ concentration, with the appearance of additional peaks related to degradation products.

Under UV light, the degradation of MDZ was 32.9\%, $47.3 \%$ and $85.3 \%$ after 7,12 and 25 days of exposition, respectively.

The graphs were constructed to determine the kinetics of photolysis degradation, obtaining the correlation coefficient: order zero $(\mathrm{r}=1)$, first order $(\mathrm{r}=0.9850)$, second order $(\mathrm{r}=$ $0.9594)$. In this way, the reaction follows zero order kinetics i.e., the degradation independent of the concentration of the reactants, and is in constant rate (14). The $\mathrm{t}_{50 \%}$ was 14.65 days. The low value of $\mathrm{t}_{50 \%}$, show that the MDZ solutions are unstable when exposed to UV light. To avoid this degradation, the manufacturers, particularly of the injections, should use amber glass vials.

Forced degradation showed higher degradation of MDZ in thermal and neutral condition, followed by acidic and basic.

The stability of MDZ solutions was investigated under mercury lamp and day light (15). From their experiments, they noticed the presence of deteriorated products: 6-(8chloro-1-methyl-4,5-dihydro-2,5,10 $b$-triazabenzo) [e]azulen-6-ylidene)-cyclohexa-2,4-dienone and 6-chloro-2methyl-4-(2-fluorophenyl)-quinazoline and 6-chloro-2methyl-4(1H)-quinazolinone.

Moreover, the aqueous MDZ solutions were evaluated under different $\mathrm{pH}$. The solutions into $\mathrm{pH} 2$ and 3 preserve the diazepine ring open, which stabilizes the solution against photo decomposition. On the other hand, the ring of MDZ molecule closes when submitted to $\mathrm{pH}$ over 4 , which it is less stable and it can be decomposed under light. Therefore, the solutions must be stored in the absence of light (avoiding the photodecomposition) and may be manufactured at the minimum $\mathrm{pH}$ allowed (15).

\section{Linearity, $L O D$ and $L O Q$}

The linearity of the method was demonstrated by the correlation coefficient (r) obtained by linear regression analysis of the calibration curve $(n=3)$. The equation was $y=$ $60.890 \mathrm{x}+170.328$ and $\mathrm{r}$ obtained was 0.9995 . The method was linear in the range from 50.0 - $250.0 \mu \mathrm{g} \cdot \mathrm{mL}^{-1}$. ANOVA demonstrated significant linear regression and absence of linearity deviation $(\mathrm{P}<0.05)$. LOQ and LOD calculated 
were $11.73 \mu \mathrm{g} \cdot \mathrm{mL}^{-1}$ and $3.87 \mu \mathrm{g} \cdot \mathrm{mL}^{-1}$ respectively, which indicate the adequate sensitivity of the method.

\section{Accuracy and Precision}

Table 1 shows the accuracy from the recovery (\%) of MDZ at three concentrations and the mean recovery was $99.61 \%$.

Table 1. Results from the recovery test, intra-day and inter-day precision and range investigated during robustness testing for HPLC method applied to midazolam in tablets.

\begin{tabular}{|c|c|c|}
\hline \multicolumn{3}{|c|}{ Accuracy } \\
\hline $\begin{array}{c}\% \\
\text { recovery }\end{array}$ & $\begin{array}{c}\text { Found Concentration } \\
\left(\mu \mathrm{g} \cdot \mathrm{mL}^{-1}\right)\end{array}$ & Concentration $\left(\mu \mathrm{g} . \mathrm{mL}^{-1}\right)$ \\
\hline 98.68 & 59.2 & 60 \\
\hline 100.41 & 140.58 & 140 \\
\hline 99.75 & 239.43 & 240 \\
\hline \multicolumn{3}{|c|}{ Intraday and Interday Precision $(\mathrm{n}=6)$} \\
\hline & $\%$ RSD & Precision $(n=6)$ \\
\hline & 1.11 & Day 1 \\
\hline & 0.82 & Day 2 \\
\hline & 1.47 & Day 3 \\
\hline
\end{tabular}

Robustness

\begin{tabular}{ccc}
\hline $\begin{array}{c}\text { Content } \\
(\%)\end{array}$ & Ranged Investigated & Variable \\
\hline 97.66 & 0.9 & Flow \\
\hline 98.25 & 1.1 & Mobile Phase pH \\
\hline 96.79 & 6.4 & \\
\hline 97.12 & 6.6 & \\
\hline
\end{tabular}

The repeatability (intraday) and intermediate precision (interday) of the method were determined, and the results were expressed as RSD. All data (table 1) were in accordance with the recommended, not greater than 5\% (13)

\section{Robustness}

There were no differences in the levels of MDZ found in the tested conditions (table 1), confirming the robustness. The variations in the mobile phase did not alter the retention time and the quantification of the drug.
Assay and Uniformity Content of MDZ tablets and injections

The tables $(n=20)$ presented a mean content of $98.02 \%$ (SD $\pm 0.85)$ and injections diluted in saline solution or methanol a content of $98.04 \%(\mathrm{SD} \pm 1.85)$ and $98.71 \%(\mathrm{SD} \pm 1.41)$, respectively. The results from analysis of injections injections were compared by Student's t test $(0.455<2.92, \mathrm{P}$ $<0.05)$, presenting no difference significant between the solvents methanol and saline in the content of MDZ, when these solutions are freshly prepared. The saline solution did not decrease the MDZ concentration in injections, i.e., it does not modify the stability of the drug. This result is important because the MDZ solutions were generally diluted in saline solution, and remains in this condition by hours during the infusions in patients.

These results for assay of MDZ showed satisfactory results. There are not specifications for tablets, only for injections. In this case, the content obtained was in accordance within the specifications (contains not less than $98.5 \%$ and not more than $101.5 \%$ of the declared amount of MDZ) (12).

Uniformity content of MDZ tablets and injections showed to be in accordance within the specifications. For the calculation of uniformity content, the following equation was used (12):

$$
\mathrm{AV}=\mathbf{k} . \mathbf{s}(\mathbf{1 2})
$$

Where "s" is the standard deviation and " $k$ " is the acceptability constant (equal to 2.4).

The mean $(\%) \pm$ SD for MDZ tablets and injection was: $99.95 \pm 3.80$ and $100.83 \pm 1.34$. The AV were 9.13 and 3.22 for tablets and injections, respectively, lower than L1 (L1 = 15), which is consistent with the recommendations, approving samples in this test (12).

\section{Conclusion}

The validation proved the specificity, linearity, sensibility, accuracy, precision and robustness. From the results obtained, the method development proved to be appropriate for assay of API, tablets and injections by LC and is capable to be used in daily routine of quality control laboratories. The literature does not report methods for quality control of tablets, and Brazilian Pharmacopeia does not present any monographs for quality analysis of MDZ. The developed method is indicative of stability, and it is able to quantify MDZ in presence of its degradation products. The results obtained from the forced degradation have shown that MDZ is unstable under hydrolysis (specialty neutral), thermal and UV light. In UV light, the degradation was about $30 \%$ in 7 days, demonstrating the importance to avoid the drug exposition.

\section{Conflict of interest}

The authors declare there is no conflicts of interest. 


\section{References}

1. Nogueira FL, Sakata RK. Palliative sedation of the terminal patient. Brazilian Journal of Anesthesiology. 2012 ; p. 586-592.

2. Gonçalves RDR, Cruz AAV. Oral midazolam as preanesthetic medication in blepharoplasties. 2009; p. 665-668.

3. Noranbuena C, Yanez, J, Flores V, Puentes P, Carrasco $\mathrm{P}$, Villena R. Oral ketamine and midazolam for pediatric burn patients: A prospective, randomized, double-blind study. J Pediatr Surg. 2013; 48(3):629-34.

4. Marçon F, Mathiron D, Pilard S, Lemaire-Hurtel AS, Duballe JM, Djedaini-Pilard F. Development and formulation of a $0.2 \%$ oral solution of midazolam containing $\gamma$-cyclodextrin. Int J Pharm. 2009; 279(2):244-50

5. Shekerdemian L, Bush A, Redington A. Cardiovascular effects of intravenous midazolam after open heart surgery. Arch Dis Child, 1997; 76(1):57-61

6. Bolon M, Boulieu R, Flamens C, Paulus S, Bastien O. Sédation par le midazolam en réanimation: aspects pharmacologiques et phamacocinétiques. Ann Fr Anesth Reanim. 2002; 6(21):478-92

7. Ali SM, Upadhyay SK. Complexation study of midazolam hydrochloride with $\beta$-cyclodextrin: NMR spectroscopic study in solution. Magn Reson Chem. 2008;

7(46):676-79.

8. Kaartama R, Jarho P, Savolainen J, Kokki H, Lehtonen M. Determination of midazolam and 1hydroxymidazolam from plasma by gas chromatography coupled to methane negative chemical ionization mass spectrometry after sublingual administration of midazolam. J Chromatogr B. 2011; 879(19):1668-76.

9. Svanstron C, Hansson GP, Svensson LD, Sennbro CJ. Development and validation of a method using supported liquid extraction for the simultaneous determination of midazolam and 1-hydroxy-midazolam in human plasma by liquid chromatography with tandem mass spectrometry detection. J Pharm Biomed Anal. 2012;

25(58)71-77.

10. Bosch ME, Sánchez AR. Analytical Methodologies for the Determination of Midazolam in Pharmaceuticals. Chromatographia. 2015; p. 609-619.

11. British Pharmacopoeia. British Pharmacopoeia Commission. London: The Stationery Office, 2018. CDROM.

12. ICH. Validation of Analytical Procedures: Text and Methodology Q2 (R1). International Conference on Harmonization, Geneva. 2005. Available at: https://www.ich.org/fileadmin/Public_Web_Site/ICH_P roducts/Guidelines/Quality/Q2_R1/Step4/ Q2_R1_Guideline.pdf. Accessed: 10 Jan 2012.

13. Carstensen JT, Rhodes CT. Drug Stability: Principles and practices, $3^{\text {rd }}$ ed. Dekker M. 2000.

14. Andersin R, Tammilehto S. Photochemical decomposition of midazolam IV. Study of $\mathrm{pH}$ dependent stability by high-performance liquid chromatography. Int J Pharm. 1995; 2(123):229-35. 